\title{
Prevention of secondary stroke in VA: Role of occupational therapists and physical therapists
}

\author{
Arlene A. Schmid, PhD, OTR; ${ }^{1-3 *}$ Lisa Butterbaugh, OT; $^{2}$ Courtney Egolf, OT; ${ }^{2}$ Virginia Richards, T $^{2}$ Linda $^{2}$ \\ Williams, MD $^{1,3-4}$ \\ ${ }^{1}$ Department of Veterans Affairs (VA) Health Services Research and Development Stroke Quality Enhancement \\ Research Initiative, Center of Excellence on Implementation of Evidence-Based Practices, Richard L. Roudebush VA \\ Medical Center, Indianapolis, IN; ${ }^{2}$ Indiana University School of Health and Rehabilitation Sciences, Department of \\ Occupational Therapy, Indianapolis, IN; ${ }^{3}$ Indiana University Center for Aging Research, Indianapolis, IN; \\ ${ }^{4}$ Regenstrief Institute, Inc, Indianapolis, IN
}

\begin{abstract}
Occupational therapists (OTs) and physical therapists (PTs) have the opportunity and obligation to advocate secondary stroke prevention via health promotion (HP) behaviors. This prospective survey of Department of Veterans Affairs (VA) OTs and PTs determined whether they know about VA stroke rehabilitation guidelines and whether they integrate secondary stroke prevention into poststroke rehabilitation care. Questions revolved around knowledge of VA guidelines, inclusion of stroke risk-factor modification, and HP education to patients. Thirty-four surveys (45\%) were returned from six facilities. Participants included 12 OTs and 22 PTs. Half (53\%) of the therapists were aware of the VA guidelines and nearly half (48\%) provided HP activities to patients; PTs were significantly more likely to do so than OTs $(p=0.02)$. Half of the queried therapists were unaware of the VA guidelines; increasing therapists' education about the guidelines and the necessity of HP and secondary stroke prevention may reduce veterans' risk of a second stroke. Because many stroke risk factors are modifiable and stroke survivors spend a great deal of time with the rehabilitation therapist, OTs and PTs can and should provide such education to reduce the risk of a second stroke.
\end{abstract}

Key words: health behaviors, health promotion, occupational therapists, physical therapists, prevention, rehabilitation, secondary stroke prevention, stroke, stroke risk factors, VA.

\section{INTRODUCTION}

Each year, approximately 700,000 people in the United States sustain a stroke [1]; approximately 200,000 of these are recurrent strokes. Stroke risk is increased in those who have had a stroke [2], with more than 12 percent of those with stroke or transient ischemic attack (TIA) experiencing a second stroke event within 1 year [3-4]. This increased risk persists for at least 5 years [5]. Furthermore, 15 percent of strokes are preceded by a TIA [6]. These data suggest that persons who have had a stroke or TIA should be targeted for stroke risk-prevention strategies.

Abbreviations: $\mathrm{ADL}=$ activities of daily living, $\mathrm{AHA}=$ American Heart Association, DOD $=$ Department of Defense, HP = health promotion, OT $=$ occupational therapist, OTA $=$ OT assistant, $\mathrm{PT}=$ physical therapist, PTA = PT assistant, TIA = transient ischemic attack, VA = Department of Veterans Affairs, VHA = Veterans Health Administration, VISN 11 = Veterans Integrated Service Network 11.

*Address all correspondence to Arlene A. Schmid, PhD, OTR; Rehabilitation Research Scientist, Richard L. Roudebush VAMC, 1481 W 10th Street, 11H, Indianapolis, IN 46202-5199; 317-988-3480. Email: araschmi@iupui.edu DOI: 10.1682/JRRD.2007.10.0162 
The American Heart Association (AHA) identifies numerous risk factors for stroke [7]. While some of these factors are not modifiable (e.g., age, heredity), numerous modifiable risk factors exist (e.g., atrial fibrillation, obesity, tobacco and alcohol use, hypertension, physical inactivity) [8-9]. Rodgers et al. state that prevention of a first or second stroke is possible through identification and control of stroke risk factors [10]. Modifiable risk factors are most effectively managed through a combination of lifestyle and medication management and, thus, require the combined and collaborative efforts of providers and stroke survivors [11-12].

Hoenig et al. state that stroke survivors are at an increased risk of a second stroke because of continued unhealthy lifestyle choices regarding stroke risk factors [13]. One method of encouraging lifestyle changes in stroke survivors is through health promotion (HP) and disease prevention interventions aimed at known modifiable stroke risk factors. Such factors may include diet, lifestyle and daily routine, degree of social support, amount of exercise, and sense of autonomy [14].

Department of Veterans Affairs (VA)/Department of Defense (DOD) stroke rehabilitation guidelines were published in 2005 [15] (as an executive summary of the AHA clinical practice guidelines for stroke rehabilitation [16]) and specifically identify HP and secondary stroke prevention as integral aspects of stroke rehabilitation. The inclusion of stroke prevention in the rehabilitation guidelines underscores the need for rehabilitation professionals such as occupational therapists (OTs) and physical therapists (PTs) to include prevention-oriented goals to reduce the likelihood of a second stroke.

The American Occupational Therapy Association's "Occupational Therapy Practice Framework: Domain and Process" emphasizes the support of function and occupational performance and mandates the integration of HP activity during therapy [17]. OTs focus on including participation (community integration, return to work, volunteering, social participation), which represents a step toward an integrated view of health and a relationship with HP [18]. OT wellness and HP programs with older adults have successfully demonstrated major improvements in vitality, general health, general mental health, social function, and absence of health-based role limitations [14,19-20].

The "American Physical Therapy Association Guide to Physical Therapy Practice” also emphasizes the use of HP techniques [21] and is concerned with the maximization of movement potential through promotion, preven- tion, treatment, and rehabilitation. Through qualitative interviews, Rea and colleagues found that while PTs believe they are introducing patients to HP, fewer people than desired are reached [21]. While providers, including therapists, may be knowledgeable about the impact of risk-factor modification, they may not aggressively counsel or engage individuals in behavioral modification to prevent a second stroke [22].

This study assessed whether OTs, PTs, OT assistants (OTAs), and PT assistants (PTAs) in Veterans Health Administration (VHA) Veterans Integrated Service Network 11 (VISN 11) were aware of the VA/DOD stroke rehabilitation guidelines and whether they used HP techniques and concepts during rehabilitation to assist in management of stroke risk factors and secondary stroke prevention.

\section{METHODS}

\section{Research Design}

We developed a survey to gather information from VA OTs, OTAs, PTs, and PTAs. Since our intent was to assess the rehabilitation therapists' use of HP in their current clinical practice, we structured the survey similarly to a prior survey assessing physician inclusion of HP interventions with patients [23]. Key objectives of the survey were to determine (1) whether VISN 11 rehabilitation therapists incorporate HP techniques into stroke rehabilitation interventions and (2) whether these practicing therapists were aware of the VA/DOD stroke rehabilitation guidelines [15-16] and their perspective practice framework/guideline. Before distribution to VA therapists, the survey was completed by community therapists for pilot testing and to gain feedback. After receiving feedback, we modified the survey according to suggestions and once again offered it to community therapists for review. This study was approved by the Clarian/Indiana University Internal Review Board and the VA Office of Research and Development. In addition, the VISN 11 VHA Labor Union granted permission to survey therapists.

\section{Survey}

The surveys were completed anonymously, but therapists were asked to identify the VA facility where they worked; whether they were an OT, OTA, PT, or PTA; their highest level of education; time since graduation; years of experience; and years of experience at the VA. Therapists were then asked specifically about the stroke 
rehabilitation they provide and whether the facility or the VA provides or incorporates stroke rehabilitation guidelines. Finally, the therapists answered questions about HP and secondary stroke prevention. Therapists were asked whether HP was part of the VA/DOD guidelines or their practice framework/guidelines. Therapists were also asked to identify stroke risk factors addressed during treatment and how such factors are addressed. An additional item was used to query the therapists on referrals made to other healthcare professionals for HP and secondary stroke prevention reasons. Identification of patients' barriers to physical activity and participation in the community were also addressed. Most items were answered with a check box, but space was always available in which additional information could be written. The survey is available upon request.

We mailed the surveys via a "research packet" to each VISN 11 facility. Research packets included cover letters, surveys, and a stamped and addressed manila envelope for survey return. In accordance with VA guidelines, surveys were not completed during work hours. Each VISN 11 facility was contacted on two occasions to assure that surveys were received and facilitate a prompt return.

\section{Participants}

We contacted each facility before the survey mailing to identify the number of therapists. The necessary number of surveys was mailed to each facility, resulting in 75 surveys being distributed throughout eight VISN 11 facilities. Inclusion criteria for participation in the study consisted of (1) being a practicing therapist (OT, OTA,
PT, or PTA) at a VISN 11 VA medical center, (2) being either a full- or part-time VA employee, (3) having a minimum of 6 months experience before the start of the study, (4) having treated at least five patients with stroke in the last year, (5) having seen a minimum of five patients in the last 6 months, and (6) agreeing to volunteer for the study by completing the survey. Surveys were excluded if half or more of the items were not completed.

\section{Data Management and Analysis}

Data entry and analysis were completed with SPSS (SPSS, Inc; Chicago, Illinois). Data were entered, checked for any errors, and saved to a secure server. We computed descriptive statistics and comparisons between groups by using Student's $t$-tests or chi-square analyses when appropriate. Comparison groups included therapist type (OT vs PT) and years of experience ( $\leq 10$ years vs $>10$ years). OTs and OTAs $(n=12)$ and PTs and PTAs $(n=22)$ were combined for the purpose of the therapist-type analysis.

\section{RESULTS}

A total of 34 completed surveys (45\%) were returned from six of the eight facilities. Represented facilities include both urban settings with more than 10 therapists and smaller, more rural facilities with less than 5 therapists.

Survey participants included 12 OTs (11 OTs and 1 OTA) and 22 PTs (17 PTs and 5 PTAs); see Table 1 for

Table 1.

Characteristics of participating Department of Veterans Affairs (VA) rehabilitation therapists.

\begin{tabular}{|c|c|c|c|}
\hline Characteristic & All & $\mathbf{O T}$ & PT \\
\hline Total, No. (\%) & $34(100)$ & $12^{*}(35)$ & $22^{\dagger}(65)$ \\
\hline Female, No. (\%) & $19(56)$ & $5(15)$ & $14(41)$ \\
\hline Years Experience as Therapist, Mean \pm SD & $15.32 \pm 11.20$ & $16.33 \pm 9.56$ & $14.31 \pm 12.84$ \\
\hline Patients with Stroke Treated/Seen per Month, Mean \pm SD & $3.13 \pm 1.70$ & $4.10 \pm 2.28$ & $2.65 \pm 1.09$ \\
\hline \multicolumn{4}{|l|}{ Education, No. (\%) } \\
\hline Master’s & $6(18)$ & $3(25)$ & $3(14)$ \\
\hline Doctorate & $5(15)$ & 0 & $5(23)$ \\
\hline Missing & $2(6)$ & $1(8)$ & 0 \\
\hline $\begin{array}{l}{ }^{*} \mathrm{OT}+\mathrm{OTA}=12 . \\
{ }^{\dagger} \mathrm{PT}+\mathrm{PTA}=22 . \\
{ }^{{ }} \text {Statistically different with 2-tailed } t \text {-test, } p=0.02 . \\
\mathrm{OT}=\text { occupational therapists, OTA = OT assistant, } \mathrm{PT}=\text { physical therapis }\end{array}$ & T assistant, SD & eviation. & \\
\hline
\end{tabular}


characteristics of the therapists. Twenty-nine therapists identified their sex (19 females and 10 males). Of the 34 who responded, 12 percent held an Associate's Degree, 50 percent a Bachelor's Degree, 18 percent a Master's Degree, and 15 percent clinical Doctorates. On average (mean \pm standard deviation), OTs had significantly more years of experience providing rehabilitation care at the VA than did PTs $(14.41 \pm 8.64$ yr vs $7.31 \pm 7.73$ yr, respectively; $p=0.02)$. Otherwise no significant differences were found between OT and PT practitioner demographics.

Of all therapists, 48 percent provide HP activities to their patients (see Table 2). PTs were significantly more likely to provide HP activities (65\%) than OTs (18\%) after stroke $(p=0.02)$. Importantly, only 53 percent of all VA practicing therapists knew that VA/DOD stroke rehabilitation guidelines exist. However, 80 percent of those who knew about the VA/DOD stroke rehabilitation guidelines knew that the guidelines include HP and prevention of a secondary stroke.
The most common HP topics addressed were physical activity/exercise (46\%), smoking (32\%), and blood pressure (29\%) (Table 3). The therapists most recently graduated ( $\leq 10$ years of experience) more often addressed $\mathrm{HP}$, risk factor modification, and prevention of secondary stroke.

Commonly addressed stroke risk factors identified by therapists as present in their patients included diabetes (97\%), hypertension (91\%), and obesity (91\%). The most common risk factors therapists reported actually discussing with stroke survivors were hypertension, obesity, and smoking. Specifically, therapists reported discussing the importance of exercise, a healthy lifestyle, medication management, and general guidelines for hypertension management. Therapists identified fear of falling (82\%), depression $(79 \%)$, and cognitive changes $(76 \%)$ as the most common reasons people decrease physical activity and limit participation (community integration, return to work, volunteering, social participation, and community

Table 2.

Health promotion (HP) and Department of Veterans Affairs (VA)/Department of Defense (DOD) rehabilitation guideline awareness. Data shown as No. (\%).

\begin{tabular}{|c|c|c|c|c|c|}
\hline \multirow{2}{*}{ Variable } & \multicolumn{3}{|c|}{ Type of Therapist } & \multicolumn{2}{|c|}{ Experience at VA } \\
\hline & All & $\mathbf{O T}$ & PT & $\leq 10 \mathrm{Yr}$ & $>10 \mathrm{Yr}$ \\
\hline Total & $34(100)$ & $12^{*}(35)$ & $22^{\dagger}(65)$ & $19(59)$ & $13(41)$ \\
\hline Do You Provide HP Activity? (Yes) & $15(48)$ & $2(18)^{\ddagger}$ & $13(65)^{\ddagger}$ & $9(50)$ & $4(36)$ \\
\hline Frequency Guidelines Are Followed (Always/Sometimes) & $14(70)$ & $5(63)$ & $9(75)$ & $8(73)$ & $4(67)$ \\
\hline Is HP Part of VA/DOD Rehabilitation Guidelines? (Yes) & $24(80)$ & $7(64)$ & $17(89)$ & $13(81)$ & $9(75)$ \\
\hline $\begin{array}{l}{ }^{*} \mathrm{OT}+\mathrm{OTA}=12 . \\
{ }^{\dagger} \mathrm{PT}+\mathrm{PTA}=22 . \\
{ }^{\ddagger} \text { Statistically significant difference after Pearson chi-square, } p=0.02 . \\
\text { OT = occupational therapist, } \mathrm{PT}=\text { physical therapist. }\end{array}$ & & & & & \\
\hline
\end{tabular}

Table 3.

Health promotion lifestyle choices addressed by therapist $(n=28)$. Data shown as No. (\%).

\begin{tabular}{|c|c|c|c|c|c|}
\hline \multirow{2}{*}{ Lifestyle Choice } & \multicolumn{3}{|c|}{ Type of Therapist } & \multicolumn{2}{|c|}{ Experience at VA } \\
\hline & All & $\mathbf{O T}$ & PT & $\leq 10 \mathrm{Yr}$ & $>10 \mathrm{Yr}$ \\
\hline Physical Activity/Exercise & $13(46)$ & $2(25)$ & $10(67)$ & $9(60)$ & $3(27)$ \\
\hline Alcohol/Drug Use & $2(7)$ & $1(13)$ & $1(7)$ & 0 & $2(18)$ \\
\hline Blood Pressure & $8(29)$ & $2(25)$ & $5(33)$ & $6(40)$ & $2(18)$ \\
\hline Caffeine Intake & 0 & 0 & 0 & 0 & 0 \\
\hline Falls/Fear of Falling & $7(25)$ & $1(13)$ & $6(40)$ & $6(40)$ & $1(9)$ \\
\hline Obesity & $7(25)$ & $1(13)$ & $5(33)$ & $4(27)$ & $3(27)$ \\
\hline Smoking & $9(32)$ & $1(13)$ & $7(47)$ & $5(33)$ & $4(36)$ \\
\hline
\end{tabular}


engagement) after stroke. The top two resources respondents used to teach patients about stroke risk factors and prevention were verbal instructions (65\%) and literature/ printed sources (19\%). Notably, 35 percent of respondents reported that they do not talk to patients about future strokes.

\section{DISCUSSION}

In this sample of VA therapists, we found that about half the therapists were aware of the VA/DOD stroke rehabilitation guidelines. Importantly, we found that half the therapists worked with their clients to enhance HP and reduce the risk of a second stroke.

\section{Clinical Implications}

Our data indicate that only half of VA practicing OTs, PTs, and assistants are aware of the existing VA/DOD stroke rehabilitation guidelines [15]. These guidelines were published in 2005 and educational modules were developed to encourage VA providers, including therapists, to become familiar with them. Duncan et al. found that increased guideline adherence led to increased rehabilitation outcomes for stroke survivors [24]. Therefore, guideline implementation and optimal HP and secondary stroke prevention may be difficult when not all practicing therapist are aware of the guidelines. We found no significant difference in the knowledge or reported implementation of VA/DOD stroke rehabilitation guidelines in relation to years of experience or type of therapist. However, those most recently graduated more often discussed HP to reduce the risk of a second stroke. These results echo those of Schwartz et al. [23], who reported that practitioners who were more recently graduated were more likely to efficiently and appropriately incorporate HP behaviors into daily practice. Because 80 percent of those who were aware of the guidelines also knew about HP and secondary stroke education, education about the guidelines is a necessary step to enhance HP and secondary stroke prevention during rehabilitation.

Another important finding is that OTs were significantly less likely than PTs to incorporate HP education or interventions. This difference may be related to clinical differences, such as PTs treating gait disturbances and using the time spent walking with patients as an opportunity to discuss the benefits of physical activity (such as walking). OT and PT education also differs: PTs are more likely to receive exercise-based course work, perhaps leading them to be more confident about discussing changes in physical activity. Rea et al. found that therapists' self-efficacy in HP was significantly related to their endorsement of such changes with patients [21]. This distinction between therapists may also be related to a statistically significant difference between the OTs' and PTs' number of years at the VA. The OTs, in general, were at the VA longer and had more years of experience. Thus, some OTs may not have been provided information about HP and secondary stroke prevention during their education. Furthermore, we are unaware of the current level of $\mathrm{HP}$ and prevention training during OT and PT education.

However, HP, overall well-being, and secondary stroke prevention are integral parts of "Occupational Therapy Practice Framework: Domain and Process" [17] and VA/ DOD stroke rehabilitation guidelines [15] and, thus, clearly should be integrated into routine OT practice. OTs are well prepared in behavioral approaches and routine development and so are well positioned to help with lifestyle modification. Clark et al. found that a preventative OT program based on participation and engagement in meaningful activities positively affected patient health and well-being up to 6 months after conclusion of the program [14]. Additionally, Schmid et al. found that people who have survived a stroke or TIA want assistance from medical professionals to establish routines to monitor and manage stroke risk factors, such as blood pressure [25]. OTs are the appropriate health professionals to assist patients in developing healthy routines and medication management regimens as part of their activities of daily living (ADL); both healthy routines and medication management are part of HP to reduce the risk of a second stroke.

We found that 46 percent of therapists incorporated physical activity into HP education/training. Physical activity or exercise is commonly incorporated into successful HP programs and is a key aspect of rehabilitation programs not only to prevent disease and further disability but also to maintain function, leisure, and social participation [26]. HP activities focused on enhancing exercise have been found to be applicable and beneficial to the poststroke population. Pang et al. completed a meta-analysis and concluded that aerobic exercise is beneficial to individuals who have survived a mild to moderate stroke [27]. In addition, Eng et al. stated that stroke survivors who participated in an 8-week community-based exercise program demonstrated improvements in mobility, functional capacity, and balance [28]. Pairing this with data from Schmid et al. [29], 
who found a positive relationship between increased poststroke gait velocity and activity and participation, demonstrates that exercise-based HP activities that increase gait speed and mobility have an overall effect on quality of life. Rimmer and Wang found that aerobic-based exercise not only decreased the risk of recurrent stroke but also increased stroke survivors' ability to perform ADL and instrumental ADL, ultimately improving their perceived quality of life [30].

Clinically, therapists likely have more dedicated oneon-one time with patients after stroke than do medical physicians, nurses, and other healthcare professionals. This fact often leads to a developed clinical relationship between the therapist and patient. The therapist should take advantage of this time and the enhanced relationship to discuss the risk of a second stroke, risk-factor modification, and HP. Such communication should be included in therapist documentation. We recommend that appropriate OT and PT secondary stroke prevention interventions include American Stroke Association stroke prevention education and handouts [12] and a review of the VA/DOD stroke rehabilitation guidelines. Rehabilitation-based HP education may include the development of a routine for medication management; training in blood pressure and glucose monitoring and management (donning and doffing a blood pressure cuff and insulin injections may be affected after a stroke); a progressive exercise regimen focusing on both cardiovascular and strength changes; and referrals to appropriate healthcare professionals regarding smoking cessation, nutrition changes, and poststroke depression [15]. The AHA has published additional guidelines on the promotion of physical activity among stroke survivors to improve function and reduce disability [31].

\section{Study Limitations}

One important limitation of this study is the survey response rate, which resulted in a small sample size. While 75 percent of the facilities returned surveys, less then half (45\%) of available identified practicing therapists completed and returned the surveys. In addition, not all participants completed all portions of the survey.

In addition, a large difference existed in the number of PTs and OTs represented, with OTs and OTAs accounting for only 35 percent of the total number of respondents. This difference is somewhat attributed to the fact that fewer OTs than PTs are employed at VA hospitals but may also reflect an assumption that the role of the OT does not include provision of HP education or techniques. Some therapists indicated that HP and prevention were provided by nursing educators and were not the role of the therapist. Those who felt that HP and secondary stroke prevention are the role of the nurse or facility educator may have been less likely to complete the survey.

Finally, the findings of this study cannot be generalized to all therapists. The participating therapists were all employed at VHA facilities in a regional VA network in the Midwest. Provision of rehabilitation care in the VA and the type of patients seen may differ from those at local and community hospitals where medical insurance and private payment may have an increased impact on allotted services and length of stay.

\section{Future Research}

Our data suggest that OTs and PTs have a great opportunity to more fully engage the patient with stroke in HP education and interventions to decrease the risk of a second stroke. The effectiveness of HP-based interventions needs to be explored as they relate to the patients' level of function so that HP can be incorporated into the treatment plans of all patients, not simply those who are performing higher-level activities. Therefore, future research should determine the most effective methods of implementing these guidelines among therapists and in rehabilitation settings and should evaluate whether such implementation leads to improved outcomes. Further efforts need to ensure that therapists are aware of the VA/DOD stroke rehabilitation guidelines and that they are providing the best and most appropriate care to not only improve their patients' function but to also maintain their health and well-being by engaging them in HP activities.

\section{CONCLUSIONS}

In conclusion, it is important that rehabilitation therapists include secondary stroke prevention and HP into their interventions; however, we have found that this does not necessary occur at this time. The best rehabilitation outcomes are gained when the practice guidelines are best followed. Therefore, we recommend that therapists include secondary stroke prevention into their shortand long-term goals for patients with stroke. Additionally we encourage therapists to work with their administration to gain support for such interventions during both in- and outpatient therapy. 


\section{ACKNOWLEDGMENTS}

This material is the result of work supported by a VA Health Services Postdoctoral Award, VA Center of Excellence on Implementation of Evidence-Based Practices, VA Stroke Quality Enhancement Research Initiative, Richard L. Roudebush VA Medical Center, Indianapolis, Indiana.

The authors have declared that no competing interests exist.

\section{REFERENCES}

1. Thom T, Haase N, Rosamond W, Howard VJ, Rumsfeld J, Manolio T, Zheng ZJ, Flegal K, O’Donnell C, Kittner S, Lloyd-Jones D, Goff DC Jr, Hong Y, Adams R, Friday G, Furie K, Gorelick P, Kissela B, Marler J, Meigs J, Roger V, Sidney S, Sorlie P, Steinberger J, Wasserthiel-Smoller S, Wilson M, Wolf P. American Heart Association Statistics Committee and Stroke Statistics Subcommittee. Heart disease and stroke statistics-2006 update: A report from the American Heart Association Statistics Committee and Stroke Statistics Subcommittee. Circulation. 2006;113(6): e85-151. [PMID: 16407573] Errata in: Circulation. 2006; 113(14):e696; and Circulation. 2006;114(23):e630.

2. Chobanian AV, Bakris GL, Black HR, Cushman WC, Green LA, Izzo JL Jr, Jones DW, Materson BJ, Oparil S, Wright JT Jr, Roccella EJ. Joint National Committee on Prevention, Detection, Evaluation, and Treatment of High Blood Pressure; National Heart, Lung, and Blood Institute; National High Blood Pressure Education Program Coordinating Committee. Seventh report of the Joint National Committee on Prevention, Detection, Evaluation, and Treatment of High Blood Pressure. Hypertension. 2003;42(6):1206-52. [PMID: 14656957]

3. Wolf PA, Clagett GP, Easton JD, Goldstein LB, Gorelick PB, Kelly-Hayes M, Sacco RL, Whisnant JP. Preventing ischemic stroke in patients with prior stroke and transient ischemic attack: A statement for healthcare professionals from the Stroke Council of the American Heart Association. Stroke. 1999;30(9):1991-94. [PMID: 10471455]

4. Lai SM, Alter M, Friday G, Sobel E. A multifactorial analysis of risk factors for recurrence of ischemic stroke. Stroke. 1994;25(5):958-62. [PMID: 8165690]

5. Acute ischemic stroke: New concepts of care. San Francisco (CA): Genentech Inc; 1998-1999.

6. Hankey GJ. Impact of treatment of people with transient ischemic attacks on stroke incidence and public health. Cerebrovasc Dis. 1996;6(Suppl 1):26-33.

7. Goldstein LB, Adams R, Alberts MJ, Appel LJ, Brass LM, Bushnell CD, Culebras A, Degraba TJ, Gorelick PB, Guyton
JR, Hart RG, Howard G, Kelly-Hayes M, Nixon JV, Sacco RL. American Heart Association/American Stroke Association Stroke Council; Atherosclerotic Peripheral Vascular Disease Interdisciplinary Working Group; Cardiovascular Nursing Council; Clinical Cardiology Council; Nutrition, Physical Activity, and Metabolism Council; Quality of Care and Outcomes Research Interdisciplinary Working Group; American Academy of Neurology. Primary prevention of ischemic stroke: A guideline from the American Heart Association/American Stroke Association Stroke Council: Cosponsored by the Atherosclerotic Peripheral Vascular Disease Interdisciplinary Working Group; Cardiovascular Nursing Council; Clinical Cardiology Council; Nutrition, Physical Activity, and Metabolism Council; and the Quality of Care and Outcomes Research Interdisciplinary Working Group: The American Academy of Neurology affirms the value of this guideline. Stroke. 2006;37(6):1583-1633. [PMID: 16675728] Erratum in: Stroke. 2007;38(1):207.

8. Gorelick PB, Sacco RL, Smith DB, Alberts M, MustoneAlexander L, Rader D, Ross JL, Raps E, Ozer MN, Brass LM, Malone ME, Goldberg S, Booss J, Hanley DF, Toole JF, Greengold NL, Rhew DC. Prevention of a first stroke: A review of guidelines and a multidisciplinary consensus statement from the National Stroke Association. JAMA. 1999; 281(12):1112-20. [PMID: 10188663$]$

9. Sacco RL, Adams R, Albers G, Alberts MJ, Benavente O, Furie K, Goldstein LB, Gorelick P, Halperin J, Harbaugh R, Johnston SC, Katzan I, Kelly-Hayes M, Kenton EJ, Marks M, Schwamm LH, Tomsick T. American Heart Association; American Stroke Association Council on Stroke; Council on Cardiovascular Radiology and Intervention; American Academy of Neurology. Guidelines for prevention of stroke in patients with ischemic stroke or transient ischemic attack: A statement for healthcare professionals from the American Heart Association/American Stroke Association Council on Stroke: Co-sponsored by the Council on Cardiovascular Radiology and Intervention: The American Academy of Neurology affirms the value of this guideline. Stroke. 2006;37(2):577-617. [PMID: 16432246]

10. Rodgers H, Greenaway J, Davies T, Wood R, Steen N, Thomson R. Risk factors for first-ever stroke in older people in the north east of England: A population-based study. Stroke. 2004;35(1):7-11. [PMID: 14657457]

11. Kenner ME, Kelley RE. Update on stroke prevention. Compr Ther. 2005;31(2):113-18. [PMID: 15901940]

12. Patient education and support [Internet]. Dallas (TX): American Stroke Association; c2005 [revised 2008 Aug 5; cited 2008 Sep 25]. Available from: http://www.strokeassociation.org/presenter.jhtml?identifier $=3030084 /$.

13. Hoenig H, Nusbaum N, Brummel-Smith K. Geriatric rehabilitation: State of the art. J Am Geriatr Soc. 1997;45(11): 1371-81. [PMID: 9361665] 
14. Clark F, Azen SP, Zemke R, Jackson J, Carlson M, Mandel D, Hay J, Josephson K, Cherry B, Hessel C, Palmer J, Lipson L. Occupational therapy for independent-living older adults. A randomized controlled trial. JAMA. 1997;278(16): 1321-26. [PMID: 9343462]

15. Bates B, Choi JY, Duncan PW, Glasberg JJ, Graham GD, Katz RC, Lamberty K, Reker D, Zorowitz R; U.S. Department of Defense; Department of Veterans Affairs. Veterans Affairs/Department of Defense clinical practice guideline for the management of adult stroke rehabilitation care: Executive summary. Stroke. 2005;36(9):2049-56. [PMID: 16120847]

16. Duncan PW, Zorowitz R, Bates B, Choi JY, Glasberg JJ, Graham GD, Katz RC, Lamberty K, Reker D. Management of adult stroke rehabilitation care: A clinical practice guideline. Stroke. 2005;36(9):100-43. [PMID: 16120836]

17. Occupational therapy practice framework: Domain and process. Am J Occup Ther. 2002;56(6):609-39. [PMID: 12458855] Erratum in: Am J Occup Ther. 2003; 57(1):115.

18. Hemmingsson $H$, Jonsson $H$. An occupational perspective on the concept of participation in the International Classification of Functioning, Disability and Health-Some critical remarks. Am J Occup Ther. 2005;59(5):569-76. [PMID: 16268024]

19. Scott AH. Wellness works: Community service health promotion groups led by occupational therapy students. Am J Occup Ther. 1999;53(6):566-74. [PMID: 10578434]

20. Clark F, Azen SP, Carlson M, Mandel D, LaBree L, Hay J, Zemke R, Jackson J, Lipson L. Embedding health-promoting changes into the daily lives of independent-living older adults: Long-term follow-up of occupational therapy intervention. J Gerontol B Psychol Sci Soc Sci. 2001;56(1):60-63. [PMID: 11192339]

21. Rea BL, Hopp Marshak H, Neish C, Davis N. The role of health promotion in physical therapy in California, New York, and Tennessee. Phys Ther. 2004;84(6):510-23. [PMID: 15161417]

22. Hanley DF. The challenge of stroke prevention. JAMA. 2004;291(5):621-22. [PMID: 14762042]

23. Schwartz JS, Lewis CE, Clancy C, Kinosian MS, Radany MH, Koplan JP. Internists' practices in health promotion and disease prevention. A survey. Ann Intern Med. 1991; 114(1):46-53. [PMID: 1983932]
24. Duncan PW, Horner RD, Reker DM, Samsa GP, Hoenig H, Hamilton B, LaClair BJ, Dudley TK. Adherence to postacute rehabilitation guidelines is associated with functional recovery in stroke. Stroke. 2002;33(1):167-77. [PMID: 11779907]

25. Schmid A, Damush TM, Plue L, Subramanian U, Bakas T, Williams LS. Self-management of blood pressure after stroke. Rehabil Nurs. Forthcoming 2008.

26. Rimmer JH. Health promotion for people with disabilities: The emerging paradigm shift from disability prevention to prevention of secondary conditions. Phys Ther. 1999;79(5): 495-502. [PMID: 10331753]

27. Pang MY, Harris JE, Eng JJ. A community-based upperextremity group exercise program improves motor function and performance of functional activities in chronic stroke: A randomized controlled trial. Arch Phys Med Rehabil. 2006;87(1):1-9. [PMID: 16401430]

28. Eng JJ, Chu KS, Kim CM, Dawson AS, Carswell A, Hepburn KE. A community-based group exercise program for persons with chronic stroke. Med Sci Sports Exerc. 2003; 35(8):1271-78. [PMID: 12900678]

29. Schmid A, Duncan PW, Studenski S, Lai SM, Richards L, Perera S, Wu SS. Improvements in speed-based gait classifications are meaningful. Stroke. 2007;38(7):2096-2100. [PMID: 17510461]

30. Rimmer JH, Wang E. Aerobic exercise training in stroke survivors. Top Stroke Rehabil. 2005;12(1):17-30. [PMID: 15735998]

31. Gordon NF, Gulanick M, Costa F, Fletcher G, Franklin BA, Roth EJ, Shephard T. American Heart Association Council on Clinical Cardiology, Subcommittee on Exercise, Cardiac Rehabilitation, and Prevention; the Council on Cardiovascular Nursing; the Council on Nutrition, Physical Activity, and Metabolism; and the Stroke Council. Physical activity and exercise recommendations for stroke survivors: An American Heart Association scientific statement from the Council on Clinical Cardiology, Subcommittee on Exercise, Cardiac Rehabilitation, and Prevention; the Council on Cardiovascular Nursing; the Council on Nutrition, Physical Activity, and Metabolism; and the Stroke Council. Stroke. 2004;35(5): 1230-40. [PMID: 15105522]

Submitted for publication October 5, 2007. Accepted in revised form April 30, 2008. 